\title{
Monitoring of stresses and deformations in soils by fiber optic sensors
}

\author{
L. Mosquera ${ }^{1}$ J. Basurto Pinao ${ }^{2}$ \\ ${ }^{1}$ Universidad Nacional de Ingeniería, Perú, lmosquera@uni.edu.pe \\ ${ }^{2}$ Universidad Nacional de Ingeniería, Perú, jbasurtop@yahoo.com
}

\begin{abstract}
This paper shows the application of LPG optical fiber sensors to the determination of the transmitted stress and deformation of a sample of confined soil subjected to surface loads. The transmitted stress was measured by a mechanical LPG pressure sensor and the curvature of the ground by permanent LPG sensors buried at depths of $0.1 \mathrm{~m} ; 0.2 \mathrm{~m} ; 0.4 \mathrm{~m}$ and $0.6 \mathrm{~m}$. Clay-sandy soil characteristic of UNICAMP was deposited in a cylinder of $0.8 \mathrm{~m}$ in length and $0.30 \mathrm{~m}$ in diameter. The soil was lightly compacted in $0.2 \mathrm{~m}$ layers and an LPG sensor was installed on each layer. Surface loads of up to $227 \mathrm{KPa}$ were applied to the surface of the soil, measuring axial soil deformations of less than $3 \mathrm{~mm}$ by our sensors with sensitivities of the order of $0.22 \mathrm{~mm} / \mathrm{dB}$. The values of the modulus of elasticity for this type of soil were determined from the fitting of the Boussinesq equations with the values measured by the buried LPG sensors. A Young's modulus of 5.40 MPa and a Poisson's coefficient $v=0.52$ were determined for this type of soil.
\end{abstract}

Keywords-- Soil stress, elastic constants, fiber optic sensors, LPG gratings, geotechnical monitoring.

\section{INTRODUCTION}

Knowledge of stress transmission in soils subject to surface loading as well as its deformation at different depths is of vital importance in the performance of compaction works for buildings, in the design of pavements or in the determination of changes in soil properties induced by agricultural machinery [1-6].

One of the first models of transmission of stress in soils was developed by Boussinesq in the year 1885 [7], in this model it is considered that vertical stress transmission $\left(\sigma_{z}\right)$ in the soil subjected to a surface load "q", uniformly distributed on a disk of radius "a" located on its surface is given by the expression:

$$
\sigma_{z}=q\left[1-\frac{z^{a}}{\left(a^{2}+z^{2}\right)^{3 / 2}}\right]
$$

Determining, likewise, the deformation $\xi(\mathrm{z})$ of the ground, on the vertical axis, from:

$$
\xi\left[z_{-}\right]:=\frac{(1+v) q}{\pi * a^{2} * Y}\left[1-2 v+\frac{2 v * z}{\left(a^{2}+z^{2}\right)^{\frac{1}{2}}}-\frac{z^{a}}{\left(a^{2}+z^{2}\right)^{\frac{2}{2}}}\right]
$$

In this article we show the application of fiber optic sensors type LPG for the measurement of the transmitted effort $\left(\sigma_{z}\right)$ and the deformation of the soil $\left(\xi_{z}\right)$ clay-sandy, of the State University of Campinas (UNICAMP) in Sao Paulo-Brazil, at depths of up to $0.6 \mathrm{~m}$. Using the Boussinesq model, we determine the elastic constants of the soil (Young and Poisson modules) based on the adjustment of the theoretical model with the stress and strain values measured by the LPG sensors.

\section{THE FIBER OPTIC SENSORS}

To fabricate the LPG type fiber optic sensors, with the appropriate measurement range and resolution, we first calculate the strain distribution $\left(\sigma_{z}\right)$ and deformations $\left(\xi_{z}\right)$ expected for the clay-sandy soil of UNICAMP, subjected to loads surface up to 227 $\mathrm{KPa}$. Young's modulus values $\mathrm{Y}=4.6 \mathrm{MPa}$ and Poisson's modulus $v=0.5$ were used in this simulation for this type of soil in according to the values obtained using other techniques [8-13]. The results of the simulations showed, for a surface load of 227 $\mathrm{kPa}$, a transmitted stress of less than $1 \%$ and a soil deformation of less than $2 \%$ of the maximum deformation at only a depth of 0,6 $\mathrm{m}$.

A. Mechanical LPG sensors

Determined the range of variation of the transmitted effort, we decided to use mechanical LPG fiber optic sensors of $600 \mu \mathrm{m}$ of period and $15 \mathrm{~mm}$ of length $[14,17]$ to measure this parameter.

Figure 1a shows the variation of the transmittance of this sensor subjected to loads up to $101 \mathrm{KPa}$. A sensitivity of 25,854 $\mathrm{dBnm} / \mathrm{KPa}$ is determined for this sensor from the linear adjustment of the data.

Digital Object Identifier (DOI): http://dx.doi.org/10.18687/LACCEI2018.1.1.416

ISBN: 978-0-9993443-1-6

ISSN: 2414-6390

$1^{\text {th }}$ LACCEI International Multi-Conference for Engineering, Education, and Technology: "Innovation in Education and Inclusion", 19-21 July 2018, Lima, Peru. 


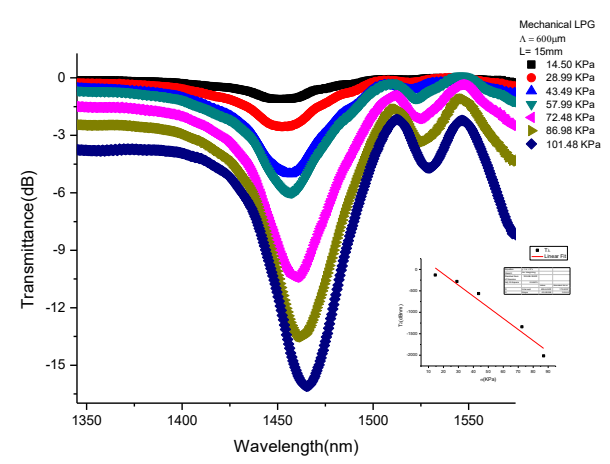

Fig. 1 Changes in amplitude and phase of the transmittance of the mechanical fiber optic LPG sensor subjected to loads up to $101 \mathrm{KPa}$. The inset show the linear response of the LPG sensor.

\section{B. Sensors engraved on the fiber with $\mathrm{CO}_{2}$ laser}

The flexural sensitivity of the grating recorded in single mode fibers with $\mathrm{CO}_{2}$ laser and the technique to determine their sensitivity to curvature changes are explained in the references [14, 17].

We fabricated LPG gratings with different sensitivities so as not to exceed the linear region of response to curvature (Fig. 2). The most sensitive LPGs were placed at a greater depth, where the stress transmitted and the deformation of the soil presented the lowest values.

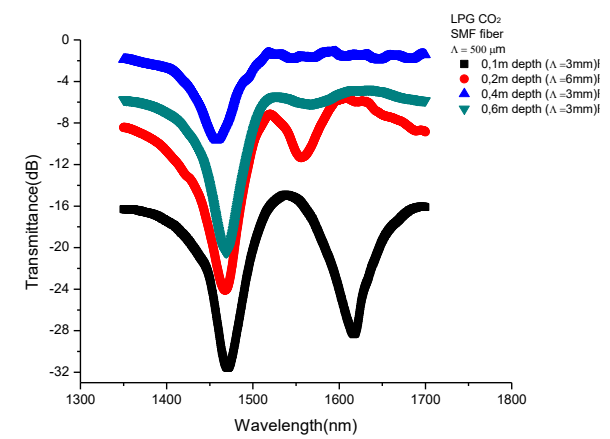

Fig. 2 LPG gratings recorded in single mode fiber using a $\mathrm{CO}_{2}$ laser.

Figure 3 shows the sensitivity of the LPG sensor (F19) to changes in the curvature of the fiber. A sensitivity of $0.224 \mathrm{~mm} / \mathrm{dB}$ was determined for this LPG.

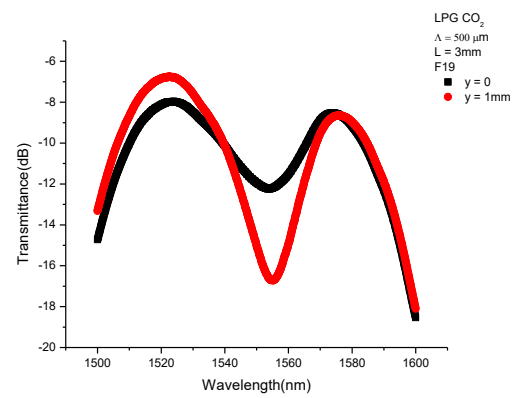

Fig. 3 Change in the transmittance of the LPG sensor (F19) subjected to curvature with $1 \mathrm{~mm}$ arrow.

\section{MEASUREMENTS}

A cylinder of $0.305 \mathrm{~m}$ diameter and $0.8 \mathrm{~m}$ length was filled with clay-sandy soil obtained from the diabasic residual soil of UNICAMP. A first layer of $0.2 \mathrm{~m}$ thickness was compacted, placing on this surface the first optical fiber sensor LPG (F17). The fiber was packaged to prevent deterioration and direct contact when buried in the ground.

$1^{\text {th }}$ LACCEI International Multi-Conference for Engineering, Education, and Technology: "Innovation in Education and 
An additional layer of soil $0.2 \mathrm{~m}$ thick was added, this layer was also compacted and then a second LPG sensor (F13) was placed on its surface, repeating the same procedure for each floor layer of $0.2 \mathrm{~m}$.

The compaction energy applied was $0.24 \mathrm{KNm} / \mathrm{m}^{3}$. The sensors were finally installed at depths of $0.1 \mathrm{~m}, 0.2 \mathrm{~m}, 0.4 \mathrm{~m}$ and $0.6 \mathrm{~m}$, on the vertical axis of the cylinder, as shown in Figure 4. The loads were applied on a circular aluminum plate of $0.1 \mathrm{~m}$ diameter placed on the surface of the soil.
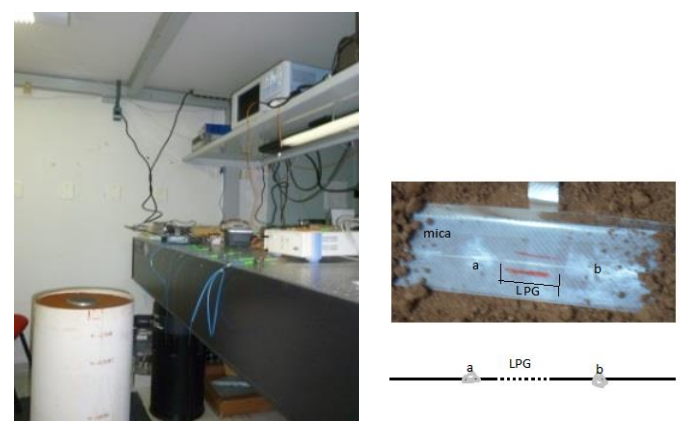

Fig. 4 This figure shows the experimental arrangement used for the determination of transmitted stresses and soil deformation.

\section{A. Measurement of soil deformation}

Figure 5 shows the variation of the transmittance of the fiber optic sensor LPG (F6) placed at the depth of $0.1 \mathrm{~m}$, when the ground surface is subject to loads of up to $226.8 \mathrm{KPa}$. The inset shows the linear response of the sensor with sensitivity of $0.030 \mathrm{~dB} / \mathrm{KPa}$.

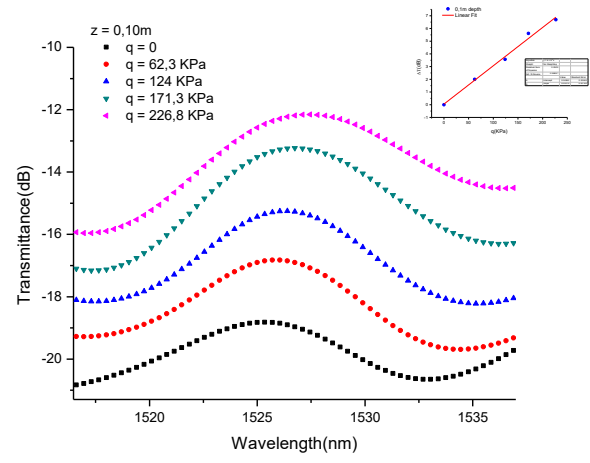

Fig. 5 The figure shows the variation of the transmittance in the LPG sensor (F6) placed at $0.1 \mathrm{~m}$ depth, when the ground is subjected to loads of up to $226.8 \mathrm{KPa}$. The inset shows the linear response of the LPG sensor.

Table I shows the calibration constants of the LPG sensors used, recorded in optical fiber single mode with CO2 laser, and the corresponding equations to determine the values of unit strain $(\xi)$ obtained when applying the loads $\sigma$ on the ground surface. The loads applied on the ground surface were $62.3 \mathrm{KPa} ; 124 \mathrm{KPa} ; 171.3 \mathrm{KPa}$ and $226.8 \mathrm{KPa}$.

TABLE I

STRESS AND STRAIN IN THE SOIL

\begin{tabular}{|c|c|c|c|}
\hline LPG & Cte1 (dB/KPa) & Cte2 (mm/KPa) & $\xi=\mathrm{cte} 2 * \sigma \mathrm{s} /(\mathrm{L}-\mathrm{z})$ \\
\hline F6 & 0,030 & 0.00672 & $\xi=0.00672 * \sigma \mathrm{s} / 700$ \\
\hline F19 & 0,00903 & 0,002023 & $\xi=0.002023 * \sigma \mathrm{s} / 600$ \\
\hline F13 & 0,0049 & 0,001098 & $\xi=0.001098 * \sigma \mathrm{s} / 400$ \\
\hline F17 & 0,00428 & 0,0009587 & $\xi=0.0009587 * \sigma \mathrm{s} / 200$ \\
\hline
\end{tabular}

Digital Object Identifier: (to be inserted by LACCEI).

ISSN, ISBN: (to be inserted by LACCEI).

16 $^{\text {th }}$ LACCEI International Multi-Conference for Engineering, Education, and Technology: "Innovation in Education and Inclusion", 19-21 July 2018, Lima, Peru. 
The continuous curves in figure 6 are the best fit using equation 2 and the normalized strain data $\xi$ (points) obtained using the relationships shown in table 1.
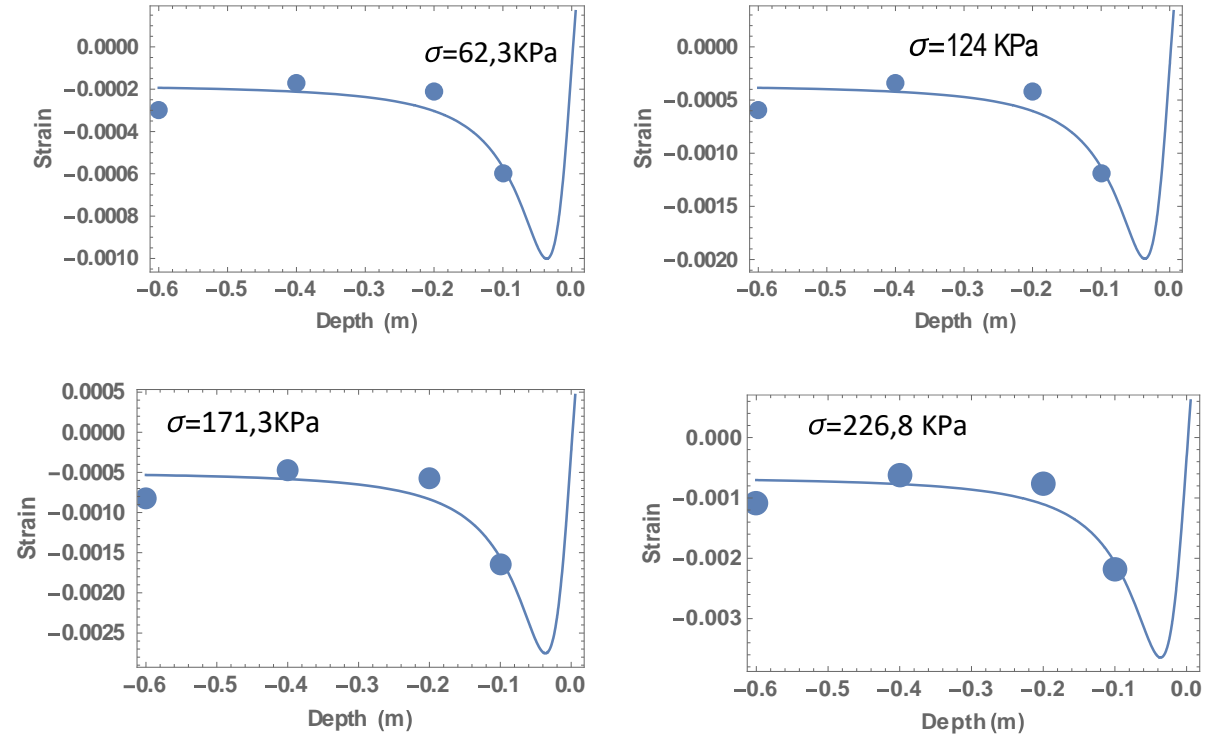

Fig 6 The points in the graphs show the values of soil deformation versus depth, as measured by the LPG sensors, when this is subjected to different surface loads. The continuous line curves are the parameter adjustment curves ( $\mathrm{Y}$ and $v$ ) using the Bousinessq equation (Eq. 2).

\section{B. Transmission of vertical soil stress}

A mechanical LPG grating $600 \mu \mathrm{m}$ of period and $20.5 \mathrm{~mm}$ of length was buried at the depth of $0.2 \mathrm{~m}$ to determine the value of the transmitted load.

Figure 7 shows the variation of the transmittance of the mechanical LPG fiber optic sensor placed at this depth while the ground was subjected to loads of up to $81.11 \mathrm{KPa}$ on its surface. Figure inset shows the slope of the linear response of the sensor when subjected to surface loads $\left(\mathrm{m}_{0}=25,854 \mathrm{dBnm} / \mathrm{KPa}\right)$ and the slope of its linear response due to the loads transmitted at $0.2 \mathrm{~m}$ depth $\left(\mathrm{m}_{0,2}=22,638 \mathrm{dBnm} / \mathrm{KPa}\right)$.

The quotient of these slopes $\mathrm{m}_{0,2} / \mathrm{m}_{0}$ is 0.876 . According to equation (1) of Boussinesq at this depth, the quotient of the transmitted load / expected surface charge must be $\sigma_{0.2} / \sigma_{0}=0.87$.

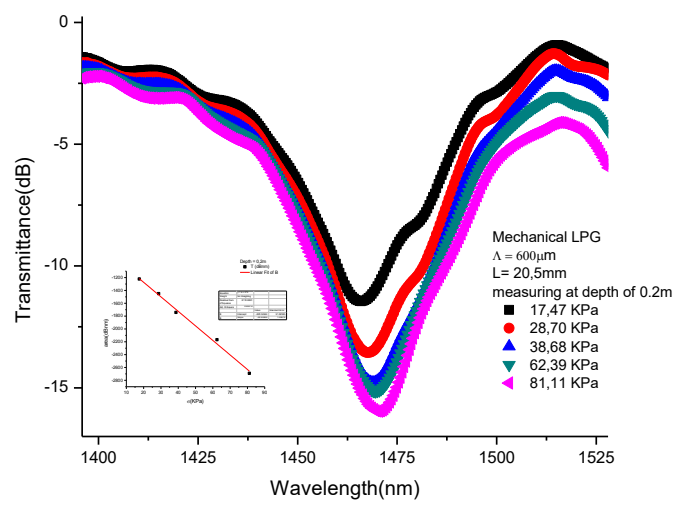

Fig 7 (a) Variation of the transmittance of the mechanical LPG sensor placed at the depth of $0.2 \mathrm{~m}$ while the ground is subjected to loads of up to $81,11 \mathrm{KPa}$ on its surface. (b) The response of the sensor is linear and its sensitivity is $22.64 \mathrm{dBnm} / \mathrm{KPa}$.

16 $^{\text {th }}$ LACCEI International Multi-Conference for Engineering, Education, and Technology: "Innovation in Education and 


\section{Determination of soil elasticity parameters}

Table II shows the values of Young's modulus and Poisson's coefficient determined by the non-linear fitting curves shown in Figure 6.

TABLE II

PARAMETERS OF SOIL ELASTICITY

\begin{tabular}{|c|c|c|}
\hline $\begin{array}{c}\text { Load on the surface } \\
(\mathrm{KPa})\end{array}$ & $\begin{array}{c}\text { Young module } \\
(\mathrm{MPa})\end{array}$ & Poisson's coefficient $v$ \\
\hline 62,3 & 5,39 & 0,52 \\
\hline 124 & 5,40 & 0,52 \\
\hline 171,3 & 5,40 & 0,52 \\
\hline 226,8 & 5,39 & 0,52 \\
\hline
\end{tabular}

\section{Conclusions}

The LPG type fiber optic sensors recorded with CO2 laser were used to measure the curvature of the soil caused by surface loads of 62.3 to $227 \mathrm{KPa}$. The mean value, measured using this technique, for Young's module $=5.40 \mathrm{MPa}$ was found in the range of values corresponding to the type of soil used (semi-compacted sandy clay) and measured by Paulo Rocha [8] using triaxial equipment.

The value found for the Poisson's coefficient $v=0.52$ contrasts with the expected value for this type of soil $v \approx 0.4$, the cause probably originates from the effect of confinement of the sample (metallic cylinder of $\mathrm{r}=0.15 \mathrm{~m}$ ).

A mechanical LPG network was used to measure the load transmitted by the soil to a depth of $0.2 \mathrm{~m}$. The values of the loads transmitted to the depth of $0.2 \mathrm{~m}$ measured by this sensor showed good agreement with the expected values from the Boussinesq equation (Eq.1).

\section{ACKNOWLEDGMENT}

We thank at the Faculty of Civil Engineering of the National University of Engineering and the staff of the research group of the Special Optical Fibers Laboratory of the University of Campinas / Brazil for the academic and technical financial support provided to develop this research.

\section{REFERENCES}

[1] T. Keller, M. Berli, S. Ruiz, M. Lamande', J. Arvidsson, P. Schjønning, A.P.S. Selvadurai, "Transmission of vertical soil stress under agricultural tyres: Comparing measurements with simulations" Soil \& Tillage Research 140, 106-117, 2014.

[2] Doohyun Kyung, Daehong Kim, Garam Kim, Incheol Kim and Junhwan Lee, "Improved Performance of Connected Foundations for Resilient Energy Transmission Infrastructure in Soft Soils" Sustainability, 8, 30, 2016; doi:10.3390/su8010030.

[3] E. A. Novikov, V. L. Shkuratnik, R. O. Oshkin, and M. G. Zaitsev, "Effect of the stress-strain state of sandy-clay soils on their thermally stimulated acoustic emission" Osnovaniya, Fundamenty i Mekhanika Gruntov, No. 2, 12-17, 2017.

[4] Sunita Mishrai, Tanusree Chakraborty, Dipanjan Basu, "High strain rate stress-strain response of soils- A review" in International Workshop on Geotechnics for Resilient Infrastructure. The Second Japan-India Workshop. Geotechnical Engineering, Volume 3, pp.80-85, 2016.

[5] Hien Nghiem, Nien-Yin Chang. "Soil-Structure Interaction Effects of High Rise. Buildings". International Conference on Case Histories in Geotechnical Engineering. 30. (2008).

[6] Zelin Zhang, Tao Wang, Shuren Wu, Huiming Tang, Peng Xin, Changyu Liang, "Dynamics stress-strain behavior of Tianshui soils" Landslides 14, 323-335, 2017.

[7] Gerd Gudehus, Physical Soil Mechanics. Springer-Verlag, 2011.

[8] Paulo José Rocha de Albuquerque "Analysis of Behavior of Small Diameter Pre-Molded Stake, Instrumentated, in Soil Residual of Diabásio of the Campinas Region" Master's thesis in Agricultural Engineering UNICAMP, 1996.

[9] M. Navarrete F. A. Godínez, M. Villagrán Muniz "Elastic Properties of Compacted Clay Soils by Laser Ultrasonics" Int J Thermophys 34, 1810-1816, 2013.

[10] Américo Hossne García "Sandy loam savanna soil elastoplasticity" SABER. Multidisciplinary Journal of the Research Council of the Universidad de Oriente, vol. 262014.

[11] Weizheng Liu, Shuai Qu, Zhihong Nie, and Junhui Zhang, "Effects of Density and Moisture Variation on Dynamic Deformation Properties of Compacted Lateritic Soil" Advances in Materials Science and Engineering Volume 2016, Article ID 5951832, http://dx.doi.org/10.1155/2016/5951832.

[12] Namkwon, Jaewon Song, and Jaehee Park "Mechanically Induced Long Period Fiber Grating Array Sensor" Microwave and Optical Technology Letters 53, 2011 .

16 $^{\text {th }}$ LACCEI International Multi-Conference for Engineering, Education, and Technology: "Innovation in Education and Inclusion", 19-21 July 2018, Lima, Peru. 
[13] L Cheng-Yu Hong, Jian-Hua Yin, Wei Jin, Chao Wang, Wan-Huan Zhou and Hong-Hu Zhu, "Comparative Study on the Elongation Measurement of a Soil Nail Using Optical Lower Coherence Interferometry Method and FBG Method" Advances in Structural Engineering Vol. 13 No. 2, 309-319. 2010.

[14] Yiping Wang "Review of long period fiber gratings written by $\mathrm{CO}_{2}$ laser" Journal of Applied Physics 108, 2010.

[15] L Mosquera, Jonas H Osório and Cristiano M B Cordeiro "Determination of Young's modulus using optical fiber long-period gratings" Meas. Sci. Technol. 27, 2016.

[16] Marrujo García Sigifredo et all. Temperature sensing on tapered single mode fiber using mechanically induced long period fiber gratings. Proc.of SPIE Vol. 9577, 95770K · ( ) 2015 SPIE. doi: 10.1117/12.2186505.

[17] J. S. Hallett, M. Partridge, S.W. James, D. Tiwari, T. Farewell, S. H. Hallett, and R. P. Tatam. Soil Moisture Content Measurement Using Optical Fiber Long Period Gratings. 25th International Conference on Optical Fiber Sensors, Proc. of SPIE Vol. 10323,@ 2017 SPIE. doi: 10.1117/12.2263427.

16 ${ }^{\text {th }}$ LACCEI International Multi-Conference for Engineering, Education, and Technology: "Innovation in Education and Inclusion", 19-21 July 2018, Lima, Peru. 